\title{
Public-Private Innovation in Health and Social Care: The Implications of Transaction Costs
}

\author{
Maren Sogstad* \\ Center for Care Research, Department of Health Sciences in Gjøvik \\ NTNU \\ Email: maren.sogstad@ntnu.no
}

\section{Eirin Lodgaard}

SINTEF Manufacturing:

\author{
Siv Magnussen \\ Department of Health Sciences in Gjøvik \\ NTNU
}

*corresponding author

\begin{abstract}
In response to the continual pressure on health and social services worldwide, there has been a demand for innovation in this sector. One area of interest has been collaboration between public and private actors in developing new solutions for service delivery. So far, knowledge of how such private-public innovation (PPI) processes emerge has been limited. We studied barriers to $\mathrm{PPI}$, focusing on how transaction costs influence the innovation process.

We conducted a single case study, following the collaborative efforts of a Norwegian municipality and a local fire and rescue company searching for new care service delivery models. The data consist of interviews with central stakeholders and documents from the PPI process. The findings add to the knowledge on barriers in public-private innovation by highlighting transaction costs as a factor influencing the PPI process. An increased awareness of transaction costs throughout the innovation process may be important in planning and resource allocation. Findings from this case study may be useful in the development and implementation of innovative ideas. Our case illustrates the need for organisational change in service innovation. A focus on transaction costs can provide a useful tool for analysing necessary structures and their consequences when beginning PPI initiatives.
\end{abstract}

Keywords: Public-private innovation, health and social care, transaction costs, Norway 


\section{Introduction}

The continuous growth of the elderly population poses a challenge for health and social care services (Eberstadt \& Groth, 2007). Due to increased needs and a reduced workforce, new care service delivery models are sought, bringing calls for innovation. According to Greenhalgh et al. (2004 p 582) innovation in service delivery can be defined 'as a novel set of behaviors, routines, and ways of working that are directed at improving health outcomes, administrative efficiency, cost effectiveness, or users' experience and that are implemented by planned and coordinated actions'. Collaborative innovation, where partners meet across organisational and cultural borders, is highlighted as a viable approach for innovations to address complex problems in public services (Bommert, 2010; Hartley et al., 2013). There has, therefore, been an increased focus on involving private actors in public innovation processes, leading to public-private innovation (PPI) (Dittmer et al., 2008; Evald et al., 2014; Nissen et al., 2014). Through the continuous transfer and discussion of ideas and knowledge, the partners in a PPI process work to develop creative solutions that the parties would be unable to reach individually (Hartley et al., 2013; Weihe et al., 2011).

Despite PPI's promising potential, the process is often challenging, and the drivers and barriers in collaborative PPI processes are still not well understood (Evald et al., 2014, Fuglsang et al., 2015). Given the call for more empirical research (Torfing \& Triantafillou, 2016), this article focus on barriers to PPI based on an empirical case study.

The case follows the collaborative efforts of a private fire and rescue company and the health and social services in a Norwegian municipality to find new ways of care service delivery. This selected innovation initiative is a rare case of collaboration in care service development between a commercial actor and a municipality in Norway, and it can thus provide valuable empirical and contextual knowledge. Studying the case, we realised that the new service provision model developed by the actors involved elements of outsourcing. Based on this observation, we found transaction cost theory (Williamson, 1975) to be a useful approach that gives novel insight into barriers in the PPI process.

While public-private interaction increases innovation, collaborative processes are time- and resource-intensive and entail transaction costs. The term 'transaction costs' refers to costs arising when one actor purchases a component or a service from another. These expenses are related to a broad 
spectrum of activities, including organisation, administration and quality control. These activities are important to ensure the safe delivery of goods and services. Transaction costs will be more thoroughly defined and discussed later in the paper. By analysing stakeholders' perspectives and reflections in contracting events, we focus on how transaction costs act as a barrier to PPI. By focusing on cost-related barriers, the transaction cost perspective provides a novel understanding of barriers in PPI initiatives. This theme may be of special interest in the Nordic context, which is characterised by a strong public health and social service sector with limited privatisation.

\section{Theoretical Framework}

\section{PPI and Collaborative Innovation}

Public-private innovation (PPI) is innovation developed by actors from both the public and private sectors working together throughout the innovation process. So far, few studies have focused on the drivers of and barriers to PPI. A literature review by Fuglsang et al. (2015) described new types of innovation networks in public services as a common theme in PPI literature, but the literature tends to approach these networks from different research perspectives based on different contextual factors, leading to a fragmented field of science. Through the theoretical perspective of innovation networks, the EU's ServPPIN project, which studied PPI networks, pointed to both internal and external factors for success; joint business cases, trust and flexible structures were shown to be important drivers, while expectation mismatch, different incentive systems and rigid public administration were emphasised as barriers (Rubalcaba et al., 2011). Cooperation between public and private actors tends to involve a strong interest in realising cost-effective and marketable solutions (Rubalcaba et al., 2011). In healthcare, PPI networks are often goal oriented, with partners coming together for a particular reason. In addition, networks are often based on previous connections between key members. The ServPPIN project showed that interaction between private, public and third sector organisations is important for the development and delivery of innovative services, and mixed forms of services are increasingly seen internationally (Rubalcaba et al., 2011). The innovative capacity of the public sector is enhanced when private actors problematise established practices and ideas (Hartley et al., 2013). Nevertheless, the widespread tendency towards institutional separation and isolation from private actors is limiting the public benefits of PPI in service innovation (Torfing \& Triantafillou, 2016). 
PPI collaboration is often advantageous, but there is a constant risk that different barriers will disrupt ongoing collaborative processes. Using institutional and organisational theories from public administration and governance, Hartley et al. (2013) summarise three challenges that can disrupt or destroy collaborative processes. First, they point to factors that bring different actors together, such as a history or tradition of interaction, motivation to spend time and energy on collaboration and the challenges of previous negative experiences with collaboration. Second, they address barriers preventing a transition from interaction to collaboration, such as conflicts of interest, mistrust and incompatible frameworks. Finally, they highlight that it can be challenging when partners become too familiar with one another, acquiring the same world view (lock-in) and thus losing their innovation potential (Hartley et al., 2013). This is in accordance with Boschma's (2005) findings on the importance of proximity in learning and innovation processes. Examining economic geographers' focus on the importance of geographical proximity, Boschma discusses the dilemma of proximity across five dimensions-cognitive, organisational, social, institutional and geographical—concluding that both too much and too little proximity constitute a problem in innovation processes (Boschma, 2005). Furthermore, collaborative innovation processes benefit from equal power resources among stakeholders (Rønning, 2015). When stronger actors dictate the premises for finding joint solutions, this can hamper dialogue and collaboration (Gray, 1989). Despite this pitfall, enthusiastic and convincing actors are necessary to achieve innovations (Magnussen, 2016). Simultaneously, the theory of public value adds the perspective of exploitation. If actors, especially private ones, are capable of exploiting the innovation process to their own advantage, this might be harmful (Benington \& Moore, 2011). Skilful leadership and management are important factors in overcoming these barriers and facilitating the collaborative process (Crosby \& Bryson, 2010).

\section{Transaction Cost Economics}

In the production of both goods and services, organisations are forced to decide what aspects of production should be performed in-house and what aspects should be bought or outsourced. Transaction cost theory is a tool for analysing these decisions and is widely used to study institutional arrangements (Klein, 2004). Transaction cost theory originated from Ronald Coase's (1937) study of the vertical and lateral integration of firms and was further developed by Williamson $(1975,1985)$ into a theory and a set of tools for analysing economic transactions and their influence on economic organisations (Klein, 2005). Thus, 
transaction cost theory poses the problem of economic organisation as a problem of contracting (Bell, 2010). Transaction costs in contracting work works like friction in physical systems, generating costs associated with cooperation in addition to the traditional production costs (Williamson, 1975). The contracting is carried out within the frame of given institutions, establishing a set of laws, rules, customs and norms to guide human behaviour (North, 1995). Different institutions, each with its own inherent governance structure, will generate different transaction costs. Consequently, transaction cost theory pays attention to institutional influence, but it does not do so as holistically as the more sociological approaches used in institutional theory (Roberts \& Greenwood, 1997).

The partners collaborating in a PPI wish to achieve a win-win situation. Their cooperation is thus not based on idealism. This draws attention to two behavioural conditions important in transaction cost theory: bounded rationality, in which individuals are constrained in their ability to act as fully informed rational agents due to limited cognitive capabilities; and opportunism, where individuals act out of self-interest and in a deliberately strategic way that is deleterious to lesser-informed parties to the contract. The pairing of these behavioural conditions within particular dimensions of the contracting environment gives rise to more complex, and therefore more costly, contracts to protect the partners from these challenges (Donato, 2010). In health and social care markets, given the extent of informational deficiencies characterising this sector with regard to quality, appropriateness and outcomes, it has been argued that hybrid governance structures supported by relational contracting are the organisational form most likely to develop (Allen et al., 2002; Ashton, 1998; Palmer \& Mills, 2003).

Several factors, including service features, uncertainty, risk and which transaction-specific investments must be made, will affect transaction costs (Carr et al., 2009; Feiock, 2007; Tavares \& Feiock, 2014). Health and social care take place in the interaction between a service provider and a service recipient. Inadequate quality in service delivery could have serious consequences for recipients. Therefore, the costs of regulating the purchase of services may be higher in this sector than in others. Services that are part of a municipality's core activities (fire services, crime prevention, etc.) are thus often produced by the municipality's own organisation (Blåka et al., 2012; Tavares \& Camöes, 2007). These services are characterised by a high cost of opportunistic behaviour among contractors and challenges in monitoring quality. The transaction cost includes all costs generated as a result of 
cooperation, such as idea generation, quality control and cooperation structures (Mick and Shay, 2016). However, it does not include costs directly associated with the production of services, or production costs. If the transaction costs are greater than the expected benefits of cooperation, new services are less likely to be offered.

Healthcare delivery is a complex sequence of transactions among patients, providers and other stakeholders. Sometimes these exchanges are concrete and observable, but most of the time they are intangible and abstract (e.g. information, advice, comfort). In the chain of transactions, the potential for transaction costs exists at every juncture (Stiles et el., 2001). Based on this recognition, using the transaction cost approach to analyse new service delivery systems created through PPI may add new insight and understanding of PPI processes in healthcare.

Several studies point to different aspects of cost as barriers to innovation in general (Hjalmarsson et al., 2014; Schroll \& Mild, 2012; Wang et al., 2012). However, we found no literature using transaction cost economics as a direct entrance to studying barriers to PPI. This article uses the theoretical perspective of transaction cost economics as an analytical framework through which to focus on contracting events and the influence of transaction costs in the PPI process.

\section{Methods}

This article uses the qualitative research approach of case study to gain insight into the informants' experiences, reflections and assessments. The case study approach was selected because it is well suited to investigate phenomena taking place in the 'real world' (Yin, 2013). Case studies help the researcher develop a nuanced view of reality by offering a detailed and multifaceted perspective on real-life situations (Flyvbjerg, 2006). The chosen case is informative, both because it bears similarities to other PPI processes and because the selected municipality already had a long tradition of purchasing services from the private company in question, a fire and rescue company. Prior to this case study, the authors had conducted a previous project in the municipality, and thus had good knowledge of the municipality and its organisation of health and social services. 


\section{Introduction to the Case}

In Norway, the responsibility of public tasks, like education, health and social care and technical infrastructure, are delegated to the local governmental and administrative level, called municipalities. Within the frames of nationally laws and expectations the municipalities have freedom to execute, develop and innovate their services. This case study followed a partnership between the health and care services in a medium sized municipality in Eastern Norway and a small local private fire and rescue company. The objective of this publicprivate initiative was to develop innovative solutions in the municipal health and care services by optimising use of competence and personnel. The innovation process studied was based on an established partnership, and thus the actors involved had already developed knowledge about and mutual trust for each other. Through a creative process, the actors sought alternative service delivery solutions in which the fire and rescue company could take over some nonmedical tasks to free healthcare personnel to focus on performing health-related duties. In total, this PPI carried out five pilot projects, each of which focused on different aspects of care service delivery: security alarms, fire safety, meal service, drug delivery and ad hoc situations.

\section{Data and Data Collection}

The data were derived from reports of working group meetings and qualitative interviews with stakeholders. The meeting reports were written as working documents for the project group and were distributed to group members and to the municipal healthcare manager. They listed the participants and summarised the discussions and decisions made. The reports were typically two pages in length and made it possible for the researchers to follow the progress, discussions and assessments made by the working group during the innovation process. In addition to analysing the reports, we performed semi-structured qualitative interviews with representatives from the public-private working group. We contacted the six group members by e-mail (two of them represented the fire and rescue company and four represented the municipality), presenting to them the purpose of the study and the main themes of the interview. Four responded positively: the project leader, the health and care service manager (who eventually withdraw from the project group, but still had valuable information from the initial part of the process ) and the leader of the home care services from the municipality and the manager of the fire and rescue company. All in all, the informants provided a good representation of the stakeholders 
involved. We developed an interview guide with open-ended questions that focused on the innovation process. The four in-depth interviews, all conducted face to face by the first and second authors, started with an introduction to the study. Each interview lasted about one hour. The interviews were recorded and transcribed verbatim before analysis.

\section{Analysis}

Following Schreiner (2012), we conducted content analysis inspired by grounded theory. Content analysis is a data-driven method to systematically describe the meaning of data by aggregating it into a more digestible form. We used transaction costs as a sensitising concept, which means that the ways in which different aspect of transaction costs appeared in the data served as a point of departure for our analysis of the barriers to PPI processes. The concept of transaction cost did not define or delimit how the data were coded. Initially, the data (both the interviews and reports) were divided into meaningful units and coded. Then, initial codes were merged into thematic categories based on similarity, forming the coding frame. Using the coding frame, relevant data were distinguished based on our interest in transaction costs as barriers to PPI. Through theoretical coding, categories were grouped according to the phases in the innovation cycle (Sørensen \& Torfing, 2011) - the generation of ideas, the selection of ideas and the implementation of ideas-and further condensed to form an understanding of the PPI process and its barriers.

\section{Reliability}

The findings in this article are based on an analysis of documents and interviews with four key actors in one innovation process. Thus, caution should be exercised in generalising the results. At the same time, the study can contribute valuable insight to a field that is currently based on limited empirical knowledge. According to Flyvbjerg (2006), case studies based on experiences and empirical evidence are important steps on the way to knowledge. This article contributes to the understanding of some aspects of barriers to PPI based on transaction cost theory. Further studies are necessary to gain a comprehensive understanding of the dynamics of PPI. 


\section{Findings}

This section presents the elements and activities identified as generating transaction costs and their influence on the innovation process in the three stages of the innovation cycle: idea generation, idea selection and idea implementation.

\section{Generation of ideas: Motivation, curiosity and trust}

The starting point of the PPI process is the contracting moment. The municipal and fire and rescue company leaders agreed to enter into the project hoping to develop a mutually beneficial service product. According to transaction cost theory, the costs related to this idea-generating phase are transaction costs. At this point, the costs we identified were mainly related to salary for the personnel involved. A one-day idea-generating seminar was arranged, and a group of six persons was established to organise the project. Additionally, the municipality spent some resources anchoring the project, both at the councillor level and further down in the organisation. However, the project partners did not reflect on aspects related to transaction costs in this phase. For instance, they did not establish a budget for the project. Both actors seemed to have a mutual understanding that the project, including the generation of ideas and the implementation of the pilots, would entail some costs, but these costs were not visualised.

The managers had the authority to make the decision to enter the PPI and to allocate resources to the project. This may be important with respect to the fact that transaction costs do not seem to be a barrier in this phase. When the leaders with the necessary authority decided to initiate the PPI, the employees took the project for granted and participated as asked. This top-down initiative may have motivated them to spend time and energy in the innovation process, as described by Hartley et al. (2013). The fact that the participants knew and trusted each other seemed to reduce the transaction costs. Curiosity and trust were important in this phase. The partners focused on the possibilities for a positive outcome. They cited different motivations for entering the innovation process. For the municipality, the continual pressure on its healthcare services was important. Given increased demands and service volume, municipal leaders needed to look for new ways of service delivery. This need was well described by the health and care service manager: 
'We wanted to see if this could be an opportunity...to maybe limit the use of overtime. Because the home care services are using considerable resources beyond budget. The services have not grown in pace with the number of duties.' (Health and care service manager)

The fire and rescue company was motivated by the possibility of creating new business. Through the cooperation, it wished to increase the knowledge and expertise of its personnel in the hope of developing service products that might be interesting for a bigger market (i.e. other municipalities).

The fire and rescue company is part of a large industrial cluster which is the main employer in the municipality. There is a long history of contact and collaboration between the industrial cluster and the municipality. The fire and rescue company and the municipality form a joint community with a common interest in creating additional value in the form of high-quality services for municipal residents and jobs in the municipality. Such shared history and interests provided the partners with common goals for the PPI process. The two actors' history of collaboration gave rise to mutual trust and the courage to commit to the project. In this initial phase of idea generation, both parties placed great emphasis on geographical proximity as a driver for innovation, as described by Boschma (2005).

\footnotetext{
'It is clear, geographical proximity means of course that it's easier to collaborate, easier to get to meet.' (Health and care service manager)

'The availability then. The proximity. I think it meant something.' (Project leader)
}

\section{Selection of Ideas: Coordination, Testing and Frustration}

During the project phase, the municipality and the fire and rescue company held regular project meetings. Initially, they presented and discussed ideas and identified areas where more knowledge was needed. Based on these needs, they initiated different service mappings as a basis for the five pilot projects described in the methods section (i.e. pilots on security alarms, fire safety, meal service, drug delivery and ad hoc situations). Then they focused on follow-up and evaluation of the pilots. This phase of the innovation cycle can be described as the selection of ideas (Sørensen \& Torfing, 2011).

The transaction costs increased during this phase, as different challenges appeared, and various barriers were exposed. The barriers leading to transaction costs were characterised by three themes: quality control, project organisation and 'lock-in'. 


\section{Quality Control}

In the development and execution of the pilots, several questions arose regarding legal issues, privacy, agreements, training, quality control and the need for new procedures. These questions became a central focus of the project group meetings. The minutes from the meetings summarise the group's discussions and plans for handling the different questions, as well as the way in which group members distributed responsibility for further follow-up. The heavy workload and the constant need for collaboration and mutual clarification are clearly reflected in the minutes. We identified the following activities as generating transaction costs: developing agreements for the pilot services, developing agreements for privacy issues, developing new work routines for information sharing, developing new workflows for both the municipality and the fire and rescue company, establishing joint routines for discrepancy processing, training fire and rescue company personnel in communication with elderly users and creating a system for technical support. As a result of the cooperation and the new routines, there was also a need for a system for continuous follow-up and evaluation.

The project leader, in particular, felt a great responsibility to ensure the quality of the services delivered and expressed the need for a system and regular meetings between the two partners:

'I am so stressed about the follow-up, is everything function like it is supposed to? ...There are some faulty alarms and other things we need to discuss on a regular basis.' (Project leader)

Following the increased workload, the PPI process became burdensome. Even though transaction costs were generated by the project at this stage, related to both work hours and the necessary infrastructure and equipment, they were not thematised by the group members. However, looking at the process from the outside, the volume and burden of transaction cost-generating processes emerge as a barrier to PPI.

\section{Project Organisation}

When the project was well established, the healthcare manager withdrew from the group, leaving the responsibility to carry on to the other members. Without her, both the management of and responsibility in the group became unclear. A project leader stepped up, but a feeling of uncertainty about goals and authority, along with a high turnover of group members, made it challenging for members to determine responsibilities. Maintaining the project and keeping the group 
active required sustained efforts from the project leader. The project leader felt burdened by the need to promote and monitor the process.

But I think the situation might have.... [She stops to reflect, and continues]...So someone had to keep hold of it to make progress. (Project leader)

When the project leader took charge of the processes, the frontline employees became more passive. They expressed a lack of understanding of the process and disclaimed responsibility, as the following quote from the home care manager illustrates:

If this is the best solution, it is up to the project group to find out, I think...So, it is the care manager's responsibility, I would think, to assess what it is we can instruct the service to perform in relation to purchasing services. (Home care manager)

Thus, a lack of clear project management and clear involvement and responsibility downstream in the service organisation emerged as a barrier to the innovation process. The leaders did not succeed in establishing ownership of and enthusiasm for the project group among employees. While earlier studies have shown that power inequalities and the presence of strong individuals dictating the premises for finding joint solutions might hamper dialogue and collaboration (Gray, 1989), this study indicates that there is a need for strong, enthusiastic and convincing actors with the force to steer the process (Magnussen, 2016; Rønning \& Knutagård, 2015).

\section{Lock-in}

Initially, the project had high hopes of finding new solutions, as the healthcare manager expressed:

'We entered without being fully aware of what we wanted but spent a lot of time thinking out loud together. It could be that we came upon something new that we had not thought of at all.' (Health and care service manager)

In the process, the focus remained on areas where the actors already had experience with cooperation. In the project phase, the municipality took an active role in promoting its wishes and needs while the fire and rescue company took a more passive role, primarily responding to the municipality's suggestions and weighing in on what would be possible, given the company's expertise and capacity.

Throughout the process, both the municipality and the fire and rescue company were thinking about service production in more traditional terms, and to a large 
degree, both parties held the same worldview. They had a history of collaboration, and the fire and rescue company was familiar with many aspects of the municipality's services. The two actors contributed similar knowledge regarding the non-medical tasks performed by the home care services. Thus, the fire and rescue company was not able to problematise the established practice. The lack of novel input hampered creativity and the creation of new ideas. The benefit of knowing each other well, and the geographical, organisational, cognitive and social proximity (Boschma, 2005; Hartley, 2013) that initially made it easy for the parties to enter into cooperation, became barriers to innovation. This passive outcome of the PPI process may also be viewed as a tactic to reduce transaction costs. Because the actors knew each other and had built trust over time, by continuing familiar patterns they reduced the necessary transaction costs in the collaboration. Hence, in this case, the combination of a private and a public actor was not able to trigger innovation.

\section{The Implementation Phase: Tradition, Disappointment and Resistance To Change}

At the end of the project period, after evaluating the different pilot projects, the actors entered the implementation phase, in which they needed to decide if they wanted to implement any of the piloted services in their everyday practice. This phase corresponds to the implementation of new ideas in the innovation cycle (Sørensen \& Torfing, 2011). In the implementation phase, the organisation of services and the evaluation of transaction costs appear to be important.

\section{Organisation of Services}

Based on the results of the pilot for ad hoc services, as well as redirecting alarms from frequent users, the two parties signed a contract to implement the pilot as a regular service. However, local leaders were still uncertain as to how and when to use these new services and whether there actually was a need for them. The contract was of little help, being vague and lacking description of the scope of or need for the services. There was limited awareness of the contract at the lower levels of the service organisation. There also seemed to be uncertainty regarding how to develop and follow up the redirected alarm service. Therefore, even though a contract was in place, the organisation of the services was unclear, which posed challenges for safety and quality, and the project leader expressed frustration regarding the quality routines of the new services. She was afraid they would fail due to a lack of routines and follow-up when the work of the project group ended. 
I'm so stressed out about the follow-up...We see that the project is positive; we gain quality in the services. I am so afraid that it will go too far and that there will be too many unsolved matters that make it all a manager's decision that the service will be taken back to the municipality. That's what often makes things fail, that the parties do not talk and collaborate and take things as they come. (Project leader)

This quote illustrates the challenges in the transition from project to regular services and the necessary organisational changes and structures that need to be in place for the innovation to succeed. Such structures typically generate transaction costs. The implementation of new models is known to be a challenging phase in the fulfilment of the innovation cycle (Sørensen \& Torfing, 2011).

\section{Evaluation of Transaction Costs}

While reflections on the transaction costs were absent during the initiation phase and unimportant in the project phase, they were an important part of the discussion when entering the implementation phase. The main reason ideas were rejected was that the cost of organising a task switch would exceed the potential benefits. As home care services perform multiple tasks in the same visit, new models dividing medical and non-medical tasks, as well as the following follow-up, information sharing and quality control, appeared to drive transaction costs and were not considered an effective use of resources.

Both actors pointed to the importance of evaluating transaction costs in decision-making, focusing on both direct costs in collaborating and costs related to quality control. As stated by the healthcare manager,

'There is an economic aspect to this. We need to know that the service is equally good when routed to fire and rescue company and that the cost is not higher compared to what we can deliver ourselves.' (Health and care service manager)

The fire and rescue company manager also pointed to the importance of mutually beneficial solutions:

\footnotetext{
'It must be a win-win situation in everything so it's a win for both parties. It must be feasible in that respect. For both parties.' (Manager of the fire and rescue company)
}

The budget for the home care services did not cover costs related to the new services. The home care services have a tradition of conducting multiple tasks and are run in a dynamic and flexible way. Home care staff are used to handling acute situations such as illnesses and falls, which are usually dealt with by 
reprioritising the workforce's daily tasks. Thus, the costs of such episodes are concealed as part of the total home care budget. With the new service, situations in which the home care services sought the fire and rescue company's assistance triggered a bill from the fire and rescue company to the municipality, making the cost visible. Hence, the new services challenged the traditional perception of the services as a whole and revealed a need for new ways of budgeting.

In this phase, the inequalities between the two partners, with one being a public service provider and the other a private business, also became clearer. The most challenging inequality was their different understanding of the context. While the small fire and rescue company were used to execute a specific task in a restricted environment, the health and care services constitute a complex organisation with multiple actors and tasks. These differences made the expectations of innovation speed at odds. Also, their different scope, the fire and rescue company wanting to expand their businesses and the health and care services goal to produce high quality services and public value, resulted in unclear expectations, insecurity and poorer collaboration.

\section{Evaluation of The PPI Process}

Upon completion of the project, both parties expressed a certain degree of disappointment. They had both hoped to achieve more. The fire and rescue company manager expressed the following:

'I had hoped for the project to generate more, from our point of view.' (Manager of the fire and rescue company)

He continued by explaining what he considered the main challenge:

'It is hard to find new and sustainable models, and there might be resistance to change, especially out in the performing services. In my view, the top management is positive to change, but the services are not following.' (Manager of the fire and rescue company)

His statement points to the importance of having broad involvement and good information flow in innovative processes. The project leader also questioned whether service managers have the time and capacity in their hectic schedules to be a driving force in innovation and change processes. Overall, the informants presented a picture of the innovation process as fragile, despite the involved parties' histories of trust, mutual knowledge and positive experiences. This fragility was based partly on a lack of resources dedicated to the handling of transaction cost-generating activities. 
Institutional boundaries also challenged the two parties' hopes that the innovation process would have a larger impact. In order to realise the collaboration's potential, the home care services needed to reorganise their work. Changing only certain parts of the services influenced the organisation and execution of other parts. Home care services are characterised by a high level of complexity, which complicates any kind of reorganisation. In this case, the municipality's resources were limited and the possibility for innovation seemed to be restricted to add-on innovations, in which new service solutions had a high degree of fit with established practices. Major innovations requiring reorganisation seemed to be out of reach. Reorganisation-related costs facilitate collaboration in service production and are part of the transaction costs; if innovation is to succeed, it is thus important to discuss transaction costs in PPI.

\section{Discussion}

In this case study, we have followed a PPI process involving a municipality's healthcare services and a private fire and rescue company. In our analysis, we used transaction costs as a sensitising concept to study barriers in the three phases of the PPI process, namely the generation of ideas, the selection of ideas and the implementation of ideas (Sørensen \& Torfing, 2011).

According to transaction cost theory, cooperation is less likely to take place if the transaction costs are higher than the expected benefits of cooperation. Thus, evaluating transaction costs is an important part of deciding whether to cooperate (Williamson \& Masten, 1995). Following the innovation process between the municipality and the fire and rescue company, transaction costgenerating activities appeared in all phases of the project.

Initially, the actors were part of a joint community; their geographical and social proximity made it easy to come together and gave them a mutual interest in success. They shared a trust that was based on friendship, kinship and experience. This removed the need for preliminary negotiations and formal contracts related to the start-up of the project and reduced the transaction costs in this phase. Our findings, based on transaction cost theory, thus extend the findings of Hartley et al. (2013), showing the importance of actors' history of collaboration, trust and motivation when entering an innovation project.

During the idea-generating phase, it became clear that the partners were familiar with one another. As shown by Hartley et al. (2013), familiarity hampers 
creativity in the idea phase and diminishes the potential for innovation ('lockin'). When partners know and understand each other well, familiarity makes cooperation easy and reduces transaction costs. However, this turns into a barrier for generating new ideas. The PPI process in question involved collaboration between only two partners. Given the limited outcome, including additional actors representing different perspectives and ideas might have increased the chances of successful innovation. Given the high level of motivation in this initial phase, the increased transaction costs generated by involving additional actors would most likely be accepted.

As the innovation process proceeded, the transaction cost-generating activities increased. A great effort was made to establish routines and structures in order to ensure quality in service delivery during the pilot projects. The large amount of work involved in ensuring service quality seemed to be exhausting for the project group and made it harder to maintain motivation. Moreover, it was questionable whether the project had access to sufficient resources. Following the increased workload associated with quality control, transaction costs appeared as a serious barrier to the PPI in this phase of the project.

Project organisation is known to ease the execution of innovation processes in parallel with normal routines in the healthcare sector (Andreassen et al., 2015). With adequate project organisation, the complexity that characterises the sector is reduced, leading to limited transaction costs. However, at the same time, project organisation is showed to delay the implementation of innovation, since the delegation of tasks and responsibilities in a project detaches innovation from normal routines (Andreassen et al., 2015). In accordance with these findings, our analysis showed that project organisation of the PPI process led to less engagement among local leaders and frontline employees, hampering implementation and acting as a barrier to PPI. This shows the importance of local involvement in innovation initiatives, despite the potential resulting increase in transaction costs.

In our case, the new care service solutions presented were 'add-on' services which functioned in parallel with established practices. Because of the project's limited authority and its disconnection from normal routines, the reorganisation needed to realise the potential of innovation did not happen. These results emphasise that health and social services management must be aware of the extensive changes that innovation might entail, and of the transaction costs actually involved when collaborating with private actors in new models of care service delivery. The ServPINN project identified rigid public administration as 
a barrier for innovation (Rubalcaba, 2011). The transaction cost perspective can contribute to an increased understanding of this rigidity.

Transaction costs entail a wide range of costs related to idea generation, contract negotiation, restriction of services and infrastructure and quality control. An interesting finding in this case study was that transaction costs seem to be understood both as the actual objective costs related to the new organisation of services as well as the subjective experience of the workload needed in order to develop new service delivery models. Furthermore, this subjective understanding of costs related to the restructuring of services emerged as an important barrier to innovation. Finding new ways of service delivery requires changes to established work practices. In complex structures such as the organisation of health and social services, combining new models and established practice can be difficult and demanding (Greenhalgh et al., 2004). In this case, the participants' subjective understanding of the work and costs associated with new service provision models was more important than the objective costs. The participants acted based on a given understanding of reality, bound to their traditional framework. Therefore, their assessments and decisions related to the development and implementation of new models appeared to be based on their subjective perception of potential transaction costs, rather than actual calculations.

In the final stage, the actors were also challenged by insufficient institutional proximity, leading to an increased need for transaction cost-generating structures to secure quality in service production. The fundamental driver of the fire and rescue company was to make profit, while the municipal care services focused on quality in service delivery. Traditionally, there is a resistance to the marketisation of care services in Norway (Vabø et al., 2013). This institutional mind-set may hamper creativity and the will to collaborate in finding new models of care service delivery. Thus, this case study reinforces the conclusions of previous literature on proximity as both a driver and a barrier to innovation (Boschma, 2005; Hartley et al., 2013).

A central finding in our case study was that even though transaction costs were present in all stages of the project, the actors first became aware of them when entering the implementation phase. In the phases of idea generation and idea selection, transaction costs were not visualised or discussed by the actors. This finding indicates that transaction costs did not hamper the innovation initiative in the first phase. If transaction costs were a barrier to innovative initiatives, this might prevent fruitful cooperation from taking place. Simultaneously, not 
addressing transaction costs in the first phase of the innovation process may lead to participation in innovation processes that cost more than the partners are willing to pay. Given that the main goal of the PPI is to develop a positive outcome, evaluating potential transaction costs when entering PPIs could enhance the basis for decision-making, thus ensuring the resources available for innovation are used efficiently. Taking part in PPI initiatives is a balancing act between facilitating logical decision-making and following ideas, engagement and motivation in a more intuitive manner.

\section{Conclusion}

This case study adds to the knowledge on barriers to public private innovation by highlighting transaction costs as an important factor throughout the PPI process. Collaborative innovation theory originates from a social constructivist tradition (Hartely et al., 2013). While collaborative innovation processes are complex and dynamic, the focus on transaction costs, representing an instrumental and rational tradition, may contribute to a complementary understanding of the barriers to PPI.

An increased awareness of transaction costs throughout the innovation cycle may help elucidate possible costs, which is important in planning and resource allocation. An increased awareness of costs may also enhance the willingness to take risks, an important factor in successful innovation. Findings from this case study may be useful in the development and implementation of innovative ideas. Our case illustrates the need for organisational change in service innovation. A focus on transaction costs can provide a useful tool for analysing necessary structures and their consequences when entering PPI initiatives.

\section{References}

Allen, P., Croxson, B., Roberts, J. A., Archibald, K., Crawshaw, S., \& Taylor, L. (2002). The use of contracts in the management of infectious disease related risk in the NHS internal market. Health Policy, 59(3), 257-281. https://doi.org/10.1016/S0168-8510(01)00183-X

Andreassen, H. K., Kjekshus, L. E., \& Tjora, A. (2015). Survival of the project: A case study of ICT innovation in health care. Social Science \& Medicine, 132, 62-69. https://doi.org/10.1016/j.socscimed.2015.03.016

Ashton, T. (1998). Contracting for health services in New Zealand: A transaction cost analysis. Social Science \& Medicine, 46(3), 357-367. https://doi.org/10.1016/S0277-9536(97)00164-0

Bell, C.R. (2010). Transaction cost economics in $21^{\text {st }}$ Centrury Economics: A referance handbook. Sage. http://dx.doi.org/10.4135/9781412979290.n19 
Benington, J., \& Moore, M. H. (2011). Public value in complex and changing times. In J. Benington \& M. H. Moore (Eds.), Public value: Theory and Practice (pp. 1-30). Macmillian International Higher Education. https://doi.org/10.1007/978-0-23036431-8_1

Blåka, S., Tjerbo, T., \& Zeiner, H. H. (2012). Kommunal organisering 2012. Redegjørelse for Kommunal-og regionaldepartementets organisasjonsdatabase. [Municipal organisation 2012. Account of the Ministry of Local governments database] Norwegian Institute for Urban and Regional Research. https://doi.org/10.7577/nibr/rapport/2012/21

Bommert, B. (2010). Collaborative innovation in the public sector. International Public Management Review, 11(1), 15-33.

Boschma, R. (2005). Proximity and innovation: A critical assessment. Regional Studies, 39(1), 61-74. https://doi.org/10.1080/0034340052000320887

Carr, J. B., LeRoux, K., \& Shrestha, M. (2009). Institutional ties, transaction costs, and external service production. Urban Affairs Review, 44(3), 403-427. https://doi.org/10.1177/1078087408323939

Crosby, B. C., \& Bryson, J. M. (2010). Integrative leadership and the creation and maintenance of cross-sector collaborations. The Leadership Quarterly, 21(2), 211-230. https://doi.org/10.1016/j.leaqua.2010.01.003

Dittmer, P., Christiansen, C., \& Kierkegaard, G. F. (2008). Public private partnership for innovation (PPPI) in Denmark. European Public Private Partnership Law Review, 4(4), 240-242.

Donato, R. (2010). Extending transaction cost economics: Towards a synthesised approach for analysing contracting in health care markets with experience from the Australian private sector. Social Science \& Medicine, 71(11), 1989-1996. https://doi.org/10.1016/j.socscimed.2010.09.016

Eberstadt, N., \& Groth, H. (2007). Europe's coming demographic challenge: Unlocking the value of health: AEI Press.

Evald, R. M., Nissen, A. H., Clarke, H. A., \& Munksgaard, B. K. (2014). Reviewing: Crossfield public private innovation. Literature: Current research themes and future research themes yet to be explored. International Public Management Review, 15(2), 32-57.

Feiock, R. C. (2007). Rational choice and regional governance. Journal of Urban Affairs, 29(1), 47-63. https://doi.org/10.1111/j.1467-9906.2007.00322.x

Flyvbjerg, B. (2006). Five misunderstandings about case-study research. Qualitative Inquiry, 12(2), 219-245. https://doi.org/10.1177/1077800405284363

Fuglsang, L., Hulgård, L., \& Langergaard, L. L. (2015). An updated list of municipal public-private innovation studies in Europe, especially Nordic studies. Roskilde University.

Gray, B. (1989). Collaborating: Finding common ground for multiparty problems. JosseyBass.

Greenhalgh, T., Robert, G., Macfarlane, F., Bate, P., \& Kyriakidou, O. (2004). Diffusion of innovations in service organizations: Systematic review and recommendations. Milbank Quarterly, 82(4), 581-629. https://doi.org/10.1111/i.0887378X.2004.00325.x

Hartley, J., Sørensen, E., \& Torfing, J. (2013). Collaborative innovation: A viable alternative to market competition and organizational entrepreneurship. Public Administration Review, 73(6), 821-830. https://doi.org/10.1111/puar.12136 
Hjalmarsson, A., Johannesson, P., Jüll-Skielse, G., \& Rudmark, D. (2014). Beyond innovation contests: A framework of barriers to open innovation of digital services. Paper presented at the Proceedings of the European Conference on Information Systems (ECIS) 2014 Tel Aviv.

Klein, P.G. (2005) The make-or-bye decision: Lessons from empirical studies. In C. Ménard \& M. M. Shirley (Eds.), Handbook of new institutional economics (pp. 435-464). Springer. https://doi.org/10.1007/0-387-25092-1_18

Magnussen, S. (2016). The power of enthusiasm in collaborative innovation: a case study of the power of individual action in the establishment of a local medical centre in Norway. Nordic Journal of Social Research, 7, 31-45. https://doi.org/10.7577/njsr.2100

Mick, S. F and Shay, P.D. (2016) Accontable care organizations and transaction cost economics. Medical Care Research and Review, 73(6), 649-659. https://doi.org/10.1177/1077558716640411

Nissen, A. H., Evald, R. M., \& Clarke, A. H. (2014). Knowledge sharing in heterogeneous teams through collaboration and cooperation: Exemplified through public-privateinnovationpartnerships. Industrial Marketing Management, 43(3). https://doi.org/10.1016/j.indmarman.2013.12.015

North, D. C. (1995). The new institutional economics and third world development. In J. Harriss, C. Lewis, \& J. Hunter (Eds.), The new institutional economics and third world development (pp. 17-26). Routledge. https://doi.org/10.4324/9780203444290.pt1

Palmer, N., \& Mills, A. (2003). Classical versus relational approaches to understanding controls on a contract with independent GPs in South Africa. Health Economics, 12(12), 1005-1020. https://doi.org/10.1002/hec.792

Roberts, P., \& Greenwood, R. (1997). Integrating transaction cost and institutional theories: Toward a constrained-efficiency framework for understanding organizational design adoption. The Academy of Management Review, 22(2), 346-373. https://doi.org/10.5465/amr.1997.9707154062

Rubalcaba, L., Windrum, P., Gallouj, F., Di, M., Pyka, A., Sundbo, J., \& Weber, M. (2011). ServPPIN. The contribution of public and private services to European growth and welfare, and the role of public-private innovation networks. Servppin final publishable summary report. European Commission.

Rønning, R. (2015). Innovations in social welfare and human services - the nobel art of tringulation. Paper presented at the Social Innovation Research Conference (SIRC), Shanghai. https://doi.org/10.4324/9781315849812

Rønning, R., \& Knutagård, M. (2015). Public innovation. A question of power? In R. Rønning \& M. Knutagård (Eds.), Innovation in social welfare and human services (pp. 47-57). Routledge. https://doi.org/10.4324/9781315849812

Schreier, M. (2012). Qualitative content analysis in practice: Margrit Schreier. SAGE.

Schroll, A., \& Mild, A. (2012). A critical review of empirical research on open innovation adoption. Journal für Betriebswirtschaft, 62(2), 85-118. https://doi.org/10.1007/s11301-012-0084-7

Stiles, R. A., Mick, S. S., \& Wise, C. G. (2001). The logic of transaction cost economics in health care organization theory. Health Care Management Review, 26(2), 8592. https://doi.org/10.1097/00004010-200104000-00010

Sørensen, E., \& Torfing, J. (2011). Enhancing collaborative innovation in the public

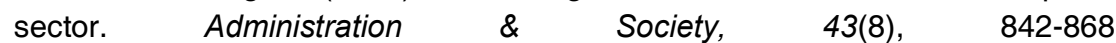
https://doi.org/10.1177/0095399711418768 
Tavares, A. F., \& Camöes, P. J. (2007). Local service delivery choices in Portugal: A political transaction costs framework. Local Government Studies, 33(4), 535-553. https://doi.org/10.1080/03003930701417544

Tavares, A. F., \& Feiock, R. C. (2014). Intermunicipal cooperation and regional governance in Europe: an institutional collective action framework. Paper presented at the European Consortium for Political Research General Conference, Glasgow, Scotland.

Torfing, J., \& Triantafillou, P. (2016). Enhancing public innovation by transforming public governance. Cambridge University Press. https://doi.org/10.1017/CBO9781316105337

Vabø, M., Christensen, K., Jacobsen, F. F., \& Trætteberg, H. D. (2013). Marketisation in Norwegian eldercare: preconditions, trends and resistance. In G. Meagher \& M. Szebehely (Eds.), Marketisation in Nordic eldercare: A research report Stockholm: Department of Social Work, Stockholm University.

Wang, Y. S., Wu, S. C., Lin, H. H., Wang, Y. M., \& He, T. R. (2012). Determinants of user adoption of web "automatic teller machines": An integrated model of "transaction cost theory" and "innovation diffusion theory". The Service Industries Journal, 32(9), 1505-1525. https://doi.org/10.1080/02642069.2010.531271

Weihe, G., Højlund, S., Holljen, T. B. E., Petersen, H. O., Vrangbæk, K., \& Ladenburg, J. (2011). Strategic use of public-private cooperation in the Nordic region. Nordic Concil of Ministers.

Williamson, O. E. (1975). Markets and hierarchies. Free Press.

Williamson, O.E. (1985). The economic institutions of capitalism. Free Press

Williamson, O. E., \& Masten, S. E. (1995). Transaction cost economics: Vol. 1: Theory and concepts. Edward Elgar.

Yin, R. K. (2013). Case study research: Design and methods. Sage publications. 